\title{
Principal Leadership Style towards Teachers' Motivation on Secondary Schools in Nigeria
}

\author{
Al-Munnir Abubakar \\ School of Education, College of Arts and Sciences \\ Universiti Utara Malaysia \\ Sintok, Malaysia \\ munirbasug@gmail.com
}

\author{
Bilyaminu Bello Inuwa \\ Department of Adult Educationline \\ Bayeayero University \\ Kano, Nigeria \\ bilyamin@gmail.com
}

\author{
Muhammad Hamma \\ Department of Education \\ Bauchi State University \\ Gadau, Nigeria \\ abuwalida@yahoo.com
}

\begin{abstract}
This study examines the relationship between principals' leadership styles applied by school and teachers' motivation in Nigerian secondary schools. The study is conceptual in nature and also the paper considers the drivers which motivate academics. The objectives of the study were to assess the effect of transformational principal leadership style on teachers' motivation and to establish the effect of transnational principal leadership style on teachers' motivation. The principal leadership style is behavior in a working process, which influences all school relevant motivation. Teachers' motivation refers to those variables, factors that power teachers do things. In its more scientific usage, teachers' motivation is to be seen as a psychological notion. It is regarded as a development of organizing behavior in progress and channeling behaviors into detailed course. It is a process of interesting, changing and at the bottom of behavior. The principal leadership style is the principal's behavior of a working process, which influences all school performances. A competent principal with leadership competencies has a great impact on teachers. He/she creates his/her management style through education, training and personal development.
\end{abstract}

Keywords—leadership style; teachers' motivation

\section{INTRODUCTION}

Education is the fundamental to the development of modern society. The most significant factors in the educational resources include quality and number of teachers' in educational institutions, quality of education, principal leadership style, work facilities and working environment. Principal and teachers help schools to achieve its goals. Principal leadership style and teachers' motivation are two very important factors of the work of the school. A large number of researches came to a conclusion that the principal leadership style is one of the most important factors that influence teachers' motivation [1].

In fostering these aims and objectives, the school principal has important roles to play. Among this role include providing effective leadership in secondary schools, thereby enhancing better motivation among teachers. How effective the principal is in performing these roles has been a matter of concern to many educationists [2]. Principal leadership in secondary schools has become one of the main concerns for many educational systems such as those in developing and developed countries, and Malaysia is no exception [3]. The problem addressed in this study involved the effects of principal leadership styles on teacher motivation and teacher efficacy. The study indicates that a principal's leadership style can influence job satisfaction and teachers' motivation [4]. Teachers' motivation in Nigeria is insignificant and teachers' are also dissatisfied with their working environment and principal leadership.

The study has investigated the relationship between educational leadership and teacher's motivation. The research described here was anchored in the convergence of two fundamental theories of leadership and motivation: the full range model of leadership and self-determination theory. The central hypotheses were that transformational leadership would predict autonomous motivation among teachers, whereas transactional leadership would predict controlled motivation. The results, based on structure equation modeling, supported the hypotheses, suggesting that leadership styles among school principals play a significant role in teachers' motivation and well-being [5].

This study examined the relationship between the principal leadership styles and the teacher's job performance in secondary schools. He found that the principal leadership style 
mostly used democratic in schools as compared to autocratic styles respectively. It is commonly used principal leadership styles in the schools. The study also showed that there is a direct relationship between principal leadership styles used and teacher job performance towards the development of education. Thus the autocratic leadership styles are the best style of leadership that can develop the yield and performance of teachers in the schools. Therefore, a successful leadership most applied both the two style democratic and autocratic styles, leadership styles towards the development of education [6].

Meanwhile, teachers also in Thailand are facing a variety of kinds of professional problem. Some of the teachers lacked commitment to their own progress. The majority of the teachers upheld the traditional work. They even lacked of good morale; some teachers refused to have behavior modify. Teachers made professional intrinsic worth by the violation of learners' times. Teachers could not participate to teach for the full session as normal hour. Some teachers did not consider in career and made a transition to another career. Teachers had no pride in the work which chose to join the early retire projects. The workload was also another reason. Teachers had too many special tasks to perform and teach too many lessons. Teachers. did not have time to work and assist students individually. Teachers' they tended to purchase ready made lesson plans accordingly. Teachers' they barely had motivation to teach for good outcome [7].

Similarly, this study investigated whether a correlation exists between the principal's leadership style and both performance level and the principal's effectiveness in schools in Dubai. The study found that the transformational leadership style was most frequently employed, followed by the transitional style, and then the passive or evident style. Finally, principal style and effectiveness differed according to the principal's gender and the level of the school, but not according to the principal's years of experience. The findings of this study open a new area of research on school principals, performance, and effectiveness in the UAE [8].

\section{TYPES OF MOTIVATION}

There are two types of motivation, Intrinsic and Extrinsic motivation. It's important to understand that we are not all the same; thus effectively motivating your employees requires that you gain an understanding of the different types of motivation [9].

\section{A. Intrinsic Motivation}

Intrinsic motivation means that the individual's motivational stimuli are coming from within. The individual has the desire to perform a specific task, because its results are in accordance with his belief system or fulfills a desire and therefore importance is attached to it. Our deep-rooted desires have the highest motivational power [10].

\section{B. Extrinsic Motivation}

Extrinsic motivation means that the individual's motivational stimuli are coming from outside. In other words, our desires to perform a task are controlled by an outside source. Note that even though the stimuli are coming from outside, the result of performing the task will still be rewarded for the individual performing the task. Extrinsic motivation is external in nature. The most well-known and the most debated motivation is money [11].

\section{TYPES OF LEADERSHIP STYLES}

Different types of leadership styles exist in work environments. Advantages and disadvantages exist within each leadership style. The culture and goals of an organization determine which leadership style fits the firm best [12].

\section{A. Laisse Faire}

A laisse faire leader lacks direct supervision of employees and fails to provide regular feedback to those under his supervision. Highly experienced and trained employees requiring little supervision fall under the laissez-faire leadership style. However, not all employees possess those characteristics.

\section{B. Autocratic}

The autocratic leadership style allows managers to make decisions alone without the input of others. Managers possess total authority and impose their will on employees. No one challenges the decisions of autocratic leaders. Countries such as Cuba and North Korea operate under the autocratic leadership style [13]

\section{Participative}

Known as a democratic leadership style, participative leadership values the input of team members and peers, but the responsibility of making the final decision rests with the participative leader. Participative leadership boosts employee morale because employees make contributions to the decisionmaking process. It causes them to feel as if their opinions matter.

\section{Transactional}

Managers using the transactional leadership style receive certain tasks to perform and provide rewards or punishments to team members based on performance results. Managers and team members set predetermined goals together, and employees agree to follow the direction and leadership of the manager to accomplish those goals.

\section{E. Transformational}

The transformational leadership style depends on high levels of communication from management to meet goals. Leaders motivate employees and enhance productivity and efficiency through communication and high visibility. This style of leadership requires the involvement of management to meet goals [14].

\section{CONCLUSION}

Principal leadership style and teachers' motivation are two very important factors in the work of the secondary school. The principal leadership style is a principal behaviour in the 
working process, what influences all school performances. Teachers' motivation can be defined as an affective attitude of teachers towards their role, derived from the evaluation of the characteristics of the job itself. The results of numerous researches indicate that leadership style influences teachers' motivation. Although controlled motivation can lead teachers to comply with the system's standards, it is the autonomous motivation that transforms their jobs into a meaningful experience, drives them to practice autonomy-supportive teaching, protects them from burnout, increases their wellbeing, improves their effectiveness, and fosters their retention in the system.

\section{ACKNOWLEDGEMENT}

This research work was done successfully and also supported by Bilyaminu Bello Inuwa of Department of Adult Education Bayero University, Kano-Nigeria. My special thanks go to the College of Arts, Sciences, Universiti Utara Malaysia for their giant moral and spiritual support.

\section{REFERENCES}

[1] Inayatullah, A., \&Jehangir, P. Teacher's job performance: The role of motivation. Abasyn 1012012. Journal of Social Sciences, 5(2), 78-99.

[2] Hardcastle, S.. Identification of the motivational techniques within Motivational Interviewing and relations with behaviour change techniques from the BCTTv1, 2014 17(3)

[3] Lai, T. T., National, T., \& Gajah, B.. School Principal Leadership Styles and Teacher Organizational Commitment among Performing Schools, 2014 10(2), 67-75

[4] Akuoko, K. O., Dwumah, P. E. T. E. R., \& Baba, W. M. Teacher Motivation 'and Quality Education Delivery: A Study of Public Basic
Schools in Tamale Metropolis in Ghana. International Journal of Social Science \& Interdisciplinary 2012 Research, 1, 12.

[5] Eyal, O., \& Roth, G. Principals ' leadership and teachers ' motivation. 2013.http://doi.org/10.1108/09578231111129055

[6] Okon, O. F,. Impact of Teacher Motivation on Academic Performance of Students Being a paper presented at National Association of Mathematics Students. 2014.

[7] Pasathang, Sarojn; Tesaputa, Kowat; Sataphonwong, Pattananusron.Teachers' Performance Motivation System in Thai Primary Schools. International Education Studies, 2016. v9 n7 p119129.

[8] Ali, S. Principal leadership style, school performance, and principal effectiveness in Dubai schools, 2013. 2(1), 41-54.

[9] Wrzesniewski, A., Schwartz, B., Cong, X., Kane, M., Omar, A., \& Kolditz, T. Multiple types of motives don't multiply the motivation of West Point cadets, 2014.

[10] Marsh, H. W., Larose, S., \& Boivin, M. Psychological Society Intrinsic, identified, and controlled types of motivation for school subjects in young elementary school children Copyright $\mathbb{C}$ ) The British Psychological Society, 2010. 6, 711735.http://doi.org/10.1348/000709910X499084

[11] Turner, A. How does intrinsic and extrinsic motivation, drive performance culture in organizations? Cogent Education, 2017 $27(1), 1$

[12] Yan, C., \& Lay, L. Are school leaders born or made? Examining factors of leadership styles of Malaysian school leaders. Procedia Social and Behavioral Sciences, 116(2005), 5120-5124 http://doi.org/10.1016/j.sbspro.2014.01.1084

[13] Lorber, M., \& Treven, S. The Examination of Factors Relating to the Leadership Style of Nursing Leaders in Hospitals, 2016. (1), 27-36. http://doi.org/10.1515/ngoe.

[14] Notter, J,Transformative Leadership at the Miami Lighthouse for the Blind," by Doug Eadie and Virginia Jacko, Associations Now, February2010. 